\title{
Internal Quality Control Using the Nordic Trollbook Yesterday, Today, and Tomorrow ${ }^{\dagger}$
}

\section{Bertil Magnusson}

Trollboken AB, s-41654 Göteborg, Sweden; berti.magnusson@trollboken.se

† Presented at the Virtual Eurachem Workshop 2020-“Quality Assurance for Analytical Laboratories in the University Curriculum", 14-15 July 2020; Available online: https://eurachem2020.ro/.

Published: 23 October 2020

Keywords: quality control; Nordtest; control charts; Trollbook

When using a method routinely in a laboratory to deliver measurement results daily to a factory to monitor a process, we can have several scenarios. The QC-internal quality control-is essential: (1) when the client trusts all the figures reported in the result, and (2) when the client is questioning the results. In both cases, you can show the client the control chart!

The chart (Figure 1) shows the client the actual variation over time within the laboratory at one concentration level. In case 1 , the client can understand that a reported result of, e.g., $63 \mu \mathrm{g} / \mathrm{L}$, is not 63.0 and could have been $58 \mu \mathrm{g} / \mathrm{L}$. In case 2 , the result of, e.g., $70 \mu \mathrm{g} / \mathrm{L}$, probably shows that the process - which usually has a concentration level of $60 \mu \mathrm{g} / \mathrm{L}-$ is out of control. Based on the control chart, the client understands that the reported result is correct and that it is most likely that the process is out of control. However, to check this, the laboratory can recommend taking a second sample to rule out any issues with sampling.

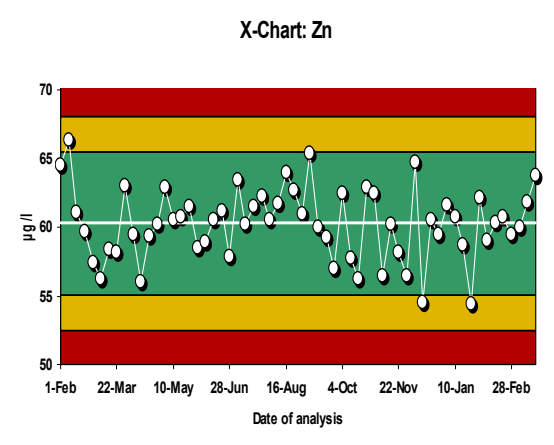

Figure 1. X-chart with warning limits within green area and action limits within yellow area. Control values are plotted versus time measured.

The first version of the Handbook of Internal Quality Control was prepared through cooperation between Nordic countries in the 1980s and is best known under the name of Trollboken. Today it can be read in more than 15 languages and is widely used as a tool in chemical laboratories (Nordtest report TR569, www.nordtest.info). Tomorrow we hope that QC will:

- Be set up using the analytical requirement, that is, using target control limits. For a process industry, the target limits are set based on process capability. For environmental laboratories, the requirement is set by regulatory authorities, and all laboratories can use the same control limits;

- Have simple rules appropriate for analytical laboratories;

- Always be available to the client; 
- Always be used in measurement uncertainty evaluation;

- Give the analyst confidence when reporting results.

The presentation introduces the basics of QC and then focuses on important issues to make internal quality control a perfect tool for the laboratory to monitor the quality of results tomorrow.

Publisher's Note: MDPI stays neutral with regard to jurisdictional claims in published maps and institutional affiliations.

(C) 2020 by the authors. Licensee MDPI, Basel, Switzerland. This article is an open access article distributed under the terms and conditions of the Creative Commons Attribution (CC BY) license (http://creativecommons.org/licenses/by/4.0/). 